\title{
Weight change during chemotherapy changes the prognosis in non metastatic breast cancer for the worse
}

Emilie Thivat ${ }^{1,2^{*}}$, Sophie Thérondel ${ }^{3}$, Olivier Lapirot ${ }^{1}$, Catherine Abrial ${ }^{1,2}$, Pierre Gimbergues ${ }^{4}$, Emilie Gadéa ${ }^{1}$, Eloïse Planchat ${ }^{1,2}$, Fabrice Kwiatkowski ${ }^{1}$, Marie A Mouret-Reynier ${ }^{2,3}$, Philippe Chollet ${ }^{1,2,3}$, Xavier Durando ${ }^{2,3}$

\begin{abstract}
Background: Weight change during chemotherapy is reported to be associated with a worse prognosis in breast cancer patients, both with weight gain and weight loss. However, most studies were conducted prior to the common use of anthracycline-base chemotherapy and on North American populations with a mean BMI classified as overweight. Our study was aimed to evaluate the prognostic value of weight change during anthracyclinebased chemotherapy on non metastatic breast cancer (European population) with a long term follow-up.

Methods: Patients included 111 women diagnosed with early stage breast cancer and locally advanced breast cancer who have been treated by anthracycline-based chemotherapy regimen between 1976 and 1989. The relative percent weight variation (WV) between baseline and postchemotherapy treatment was calculated and categorized into either weight change $(\mathrm{W}>5 \%)$ or stable $(\mathrm{WV}<5 \%)$. The median follow-up was 20.4 years [19.4 - 27.6]. Cox proportional hazard models were used to evaluate any potential association of weight change and known prognostic factors with the time to recurrence and overall survival.
\end{abstract}

Results: Baseline BMI was 24.4 kg/m2 [17.1 - 40.5]. During chemotherapy treatment, 31\% of patients presented a notable weight variation which was greater than $5 \%$ of their initial weight.

In multivariate analyses, weight change (> 5\%) was positively associated with an increased risk of both recurrence (RR 2.28; 95\% Cl: 1.29-4.03) and death (RR 2.11; 95\% Cl: 1.21-3.66).

Conclusions: Our results suggest that weight change during breast-cancer chemotherapy treatment may be related to poorer prognosis with higher reccurence and higher mortality in comparison to women who maintained their weight.

\section{Background}

Age, tumour size, axillary node status, histological tumour type and standardized pathological grade are accepted as well-defined prognostic factors in breast cancer [1]. Various studies have also reported striking associations between overweight or obesity at breast cancer diagnosis and poorer prognosis with higher distant recurrence and mortality (for review [2]). As emphasized by Goodwin et al. [3], the risk of recurrence and death was respectively 1.78 (95\% CI: $1.50-2.11)$ and

\footnotetext{
* Correspondence: Emilie.Thivat@cjp.fr

'Division of Clinical Research, Centre Jean Perrin, Clermont-Ferrand, F-63011 France; University Clermont 1, UFR Médecine, Clermont-Ferrand, F-63001 France; Centre d'Investigation Clinique, Clermont-Ferrand, F-63001 France Full list of author information is available at the end of the article
}

1.36 (95\% CI: 1.19-1.55) times greater for obese patients over a 10 years follow-up period.

Moreover, numerous studies reported a weight gain after breast cancer development that might be attributable to the effects of some treatment regimens [4,5]. Weight gain in breast cancer patients has been associated with anti-neoplastic chemotherapy in the majority of studies. Previous studies suggest that weight gain is more pronounced among premenopausal women and among those who were treated with a multiagent regimen $[6,7]$. However, few reports have not observed increased weight gain during chemotherapy $[5,8,9]$, in particular with anthracycline-containing regimens $[10,11]$
C Biomed Central 
widely recognized as the gold standard treatment of women with breast cancer.

There is also substantial evidence that weight change during chemotherapy may be associated with a worse prognosis for the cancer patient, both with weight gain [12] and weight loss [13]. The findings reported by the few studies which have explored the prognostic value of weight gain after a diagnosis of breast cancer are mixed: four studies reported that weight gain was associated with a decreased overall survival and increased recurrence risk $[8,14-16]$ whereas five others failed to report such associations $[10,9,17]$. Only one recent study reported some evidence that women with early breast cancer, who had a weight loss during treatment, were at higher risk of recurrence and death compared to women with no weight variation [18]. These discrepancies may be attributable to the heterogeneity of the methods implemented in the different studies, including the duration of post-diagnosis weight assessment, the definition of the prognostic outcomes with a short median of follow-up and treatment (chemotherapy and/or hormonotherapy...). The majority of the previous studies were conducted before anthracycline-base chemotherapy was commonly used. Additionally all the aforementioned studies focused on north American populations with a mean Body Mass Index (BMI) at breast cancer diagnosis classified as overweight $[14,19]$. However no data is available on the prognostic impact of weight change during chemotherapy treatment in European breast cancer patients who presented a notably lower BMI [20].

Our study thus investigated the prognostic value (death and recurrence) of weight variation during anthracycline-based chemotherapy treatment of breast cancer in a French population with a long-term followup. We also verified the association of weight at breast cancer diagnosis with survival.

\section{Methods}

\section{Population}

A retrospective chart review was performed using data from hospital medical records on all women with early stage breast cancer and locally advanced breast cancer who were treated at Jean Perrin Center (ClermontFerrand) between 1976 and 1989 in order to have at least 20 years of follow-up for the study. Among the 709 women treated with chemotherapy treatment for breast cancer, 111 women were included in the analysis. The study was approved by the Inter-regional Ethics Committee of the Rhône -Alpes-Auvergne Clinical Investigation Center (N'IRB5044). Subjects were selected if they had histologically confirmed stage I-III breast cancer, and received chemotherapy under the anthracycline-based chemotherapy regimen. Patients were excluded from this review if weight assessment did not include at least measurements at baseline and at the end of chemotherapy, if they had distant metastasis at diagnosis or a history of another malignancy.

\section{Weight measurements}

Weight was measured at the hospital by a nurse at the beginning of treatment and in the last chemotherapy cycle. The BMI was calculated by dividing weight $(\mathrm{kg})$ by height $(\mathrm{m})$ squared. The different subclasses of patients were categorized as followed: underweight (< 18.5), normal (18.5 - 25), overweight $(25$ - 29.9) or obese $(\geq 30)$. The median BMI being of $24.4 \mathrm{~kg} / \mathrm{m}^{2}$ rounded down to $24 \mathrm{~kg} / \mathrm{m}^{2}$ was used to median-split the population, i.e. categorized women as having BMI less than 24 , or more than $24 \mathrm{~kg} / \mathrm{m}^{2}$.

A number of studies suggest that a $5 \%$ change in body weight is clinically meaningful [5]. Weight variations (WV) were calculated as the relative percent weight changes between weight measurement from baseline to post-chemotherapy treatment ((baseline weight - weight after chemotherapy)/baseline weight $\times 100)$. WV were categorized accordingly into weight change (WV > 5\%) or stable (WV $<5 \%$ ). The weight changing group (WV > 5\%) combined women who lost weight (defined by a relative weight loss $>5 \%$ between weight measurement from baseline to post-chemotherapy treatment) and women who gained weight (defined by a relative weight gain $>5 \%$ ).

\section{Covariates}

Information on the age of patients, menopausal status, hormonal receptors, tumour stage, nodal involvement, Scarff-Bloom-Richardson (SBR) grade, and on treatment received before and after chemotherapy were obtained from reviewing patients' medical records. We used the Tumour- Node-Metastasis (TNM) classification of stage of breast cancer at diagnosis as established by the American Joint Committee on Breast Cancer [21] which consists of 3 components: (i) tumour size (T); (ii) absence or presence and extent of regional lymph node metastasis $(\mathrm{N})$; and (iii) absence or presence of distant metastasis $(\mathrm{M})$.

\section{Outcome assessment}

Deaths and recurrences were last updated in June 2009. Recurrence included a local/regional cancer recurrence, distant recurrence/metastasis, or development of a contralateral primary breast cancer. Patients who died without recurrence of breast cancer beforehand have been censored for analysis of recurrence.

The disease free survival (DFS) duration was defined as the time elapsed between the date of first diagnosis and the date of first relapse. The overall survival (OS) duration was the time elapsed between the date of initial 
diagnosis and the date of death or the last status report, whether the patient was alive or dead, whatever the cause.

\section{Statistical analyses}

Descriptive statistics were calculated for all variables used in this study and presented as median [range]. OS and DFS were estimated using Kaplan-Meier method [22]. A univariate analysis was performed using log rank methods. Parameters tested to be potentially correlated with OS or DFS were BMI and WV.

We realized multivariate analysis using Cox's proportional-hazard models [23] to evaluate the association of categories of baseline BMI and WV and well defined pronostic factors in breast cancer with the time to recurrence and mortality. Covariates considered as potential confounders in the above model included menopausal status, tumour stage, nodal involvement, and treatment after chemotherapy (hormonotherapy). A $p$ value $<0.05$ was considered to be statistically significant. Variance analysis $\left(\mathrm{Chi}^{2}\right.$ or Kruskal-Wallis $\mathrm{H}$ tests) was used to test associations between initial BMI, WW and the covariates. Analyses were conducted using SEM software version 3.5 [24].

\section{Results}

\section{Characteristics of the population}

Table 1 lists the main characteristics of patients. The median age at diagnosis was 54 years (32 - 55 years), and $55 \%$ of the women were post-menopausal at diagnosis. In all, 58 patients $(52 \%)$ had a positive hormone receptor status and among them 28 were $\mathrm{ER}+/ \mathrm{PR}+$ (25\%). Seventeen percent of the women were diagnosed with stage I breast cancer while $48 \%$ had stage II and $35 \%$ had stage III respectively. With regards to tumour characteristics, 21 patients (19\%) were T1, 49 T2 (44\%), 17 T3 (15\%) and 24 T4 (22\%), respectively. Regarding clinical node involvement, 55 patients were NO (50\%), 49 N1 (44\%), 6 N2 (5\%) and 1 N3 (1\%), respectively.

\section{Treatments}

Between 1976 and 1989, patients received a median number of 6 cycles [2-15] of polychemotherapy. The median lag time between diagnosis and the start of treatment was 1.7 months [0-9]. All patients were treated with an anthracycline-based regimen (AVCF 54\%, AVCFM 44\%, FAC 1\%, FEC 1\%). In all, 66 patients underwent a tumourectomy and 44 underwent a mastectomy. After chemotherapy, $97 \%$ received radiation and $44 \%$ a hormonal therapy (90\% with tamoxifen).

\section{BMI and weight variation}

The initial median BMI was $24.4 \mathrm{~kg} / \mathrm{m} 2$ [17.1 - $40.5 \mathrm{~kg} /$ $\mathrm{m} 2$ ]. The different subclasses of patients were distributed as followed: $9 \%$ were underweight, $56 \%$ normal, $31 \%$ overweight and $15 \%$ obese.

During chemotherapy, weight was stable with a median relative WV of 0 [-10.9 - 15.4\%]. Using a threshold of $5 \%, 17 \%$ of patients lost weight, $69 \%$ were stable and $14 \%$ gained weight. Thus, $31 \%$ of patients presented a notable $\mathrm{WV}$, higher than $5 \%$.

\section{Univariate analyses}

The median of the follow-up was 20.4 years [19.4 - 27.6]. Among the 111 women, 57 died, 14 developed a local recurrent, and 56 a distant metastasis. Only few patients died from other causes than breast cancer. Among the 57 women who died, 47 developed breast cancer recurrence (83\%). No patient was lost of follow-up. The median OS was 14.3 years [0.7 - 21.8] and median DFS 10 years [0.4 - 21]. The univariate analysis sh owed that OS ( $p=$ $0.002)$ and DFS $(p=0.0039)$ depended on tumour stage. We also found that nodal involvement influenced OS $(p<0.001)$ and DFS $(p=0.0024)$.

Concerning the initial BMI, patients with a baseline BMI of less than $24 \mathrm{~kg} / \mathrm{m}^{2}$ had a better OS than those with an initial BMI of greater than $24 \mathrm{~kg} / \mathrm{m}^{2}(p=0.024$; Figure 1A). DFS was also influenced by the BMI, as illustrated by a significant statistical difference between these two groups ( $p=0.046$; Figure 1B).

Moreover, OS and DFS were influenced by the WV. As the sample size is likely too small to detect significant effects of weight gain or loss as independent factors, we therefore chose to group women who gained weight with those who lost weight as a weight changing group compared to women with no weight variation. Indeed, a Kaplan-Meier analysis revealed a significant DFS difference between patients whose weight varied beyond $5 \%$ compared to patients who maintained their weight ( $p=0.048$; Figure $2 \mathrm{~B}$ ) while OS analysis was closed to significance $(p=0.061$; Figure $2 \mathrm{~A})$.

Variance analysis revealed a significant correlation between initial BMI and tumour stage $(p=0.0038)$, menopausal status $(p=0.00074)$ but not with clinical node involvement, hormonotherapy treatment, and WW. Results from the $\mathrm{Chi}^{2}$ test showed no significant correlation between weight variation and tumour stage, nodal involvement, menopausal status, initial BMI and administration of hormonotherapy after chemotherapy.

\section{Multivariate analysis}

The multivariate Cox model (Table 2) included WV, tumour stage, nodal involvement, initial BMI, menopausal status and treatment by hormonotherapy. As mostly patients received radiotherapy (97\%), this factor was not included in multivariate analysis.

Only WV still had a significant effect on OS. A change of weight of more than $5 \%$ was associated 
Table 1 Main characteristics of the population study

\begin{tabular}{|c|c|c|c|c|}
\hline Characteristics, $n=111$ & & $\begin{array}{l}\text { stable weight } \\
(\mathrm{n}=77)\end{array}$ & $\begin{array}{l}\text { changing weight } \\
(n=34)\end{array}$ & $P$ \\
\hline \multirow[t]{2}{*}{ Median age (years (range)) } & $54(32-74)$ & $53(37-70)$ & $54(32-74)$ & 0,49 \\
\hline & n (\%) & & & \\
\hline Median BMI & $24.4(17.1-40.5)$ & $24.6(17.1-40.5)$ & $24.4(16.6-40.5)$ & 0,14 \\
\hline underweight & $9(8)$ & $7(9)$ & $2(6)$ & \\
\hline normal & $56(50)$ & $36(47)$ & $20(59)$ & \\
\hline overweight & $31(28)$ & $21(27)$ & $10(29)$ & \\
\hline obese & $15(14)$ & $13(17)$ & $2(6)$ & \\
\hline Menopausal status & & & & 0,78 \\
\hline Premenopausal & $50(45)$ & $34(44)$ & $16(47)$ & \\
\hline Menopausal & $61(55)$ & $43(56)$ & $18(53)$ & \\
\hline Oestrogene receptors & & & & 0,61 \\
\hline Positive & $47(42)$ & $32(42)$ & $15(44)$ & \\
\hline Negative & $48(44)$ & $35(45)$ & $13(38)$ & \\
\hline Progesteron receptors & & & & 0,73 \\
\hline Positive & $39(35)$ & $29(38)$ & $10(29)$ & \\
\hline Negative & $52(47)$ & $37(48)$ & $15(44)$ & \\
\hline Tumor stage & & & & 0,99 \\
\hline $\mathrm{T}_{1}$ & $21(19)$ & $15(19)$ & $6(18)$ & \\
\hline $\mathrm{T}_{2}$ & $49(44)$ & $34(44)$ & $15(44)$ & \\
\hline $\mathrm{T}_{3}$ & $17(15)$ & $12(16)$ & $5(18)$ & \\
\hline $\mathrm{T}_{4}$ & $24(22)$ & $16(21)$ & $8(24)$ & \\
\hline Clinical node involvement & & & & 0,34 \\
\hline $\mathrm{N}_{0}$ & $55(50)$ & 34 (44) & $21(62)$ & \\
\hline$N_{1}$ & 49 (44) & $37(48)$ & $12(35)$ & \\
\hline $\mathrm{N}_{2}$ & $6(5)$ & $5(6)$ & 1 (3) & \\
\hline $\mathrm{N}_{3}$ & $1(1)$ & $1(1)$ & & \\
\hline SBR grade & & & & 0,17 \\
\hline I & $9(8)$ & $8(10)$ & $1(3)$ & \\
\hline$\|$ & $61(55)$ & $40(52)$ & $21(62)$ & \\
\hline III & $22(20)$ & $8(10)$ & $4(12)$ & \\
\hline
\end{tabular}

with an increased risk of death of 2.11 ; 95\% CI: 1.21$3.66(p=0.0082)$.

Moreover, we found that WV was associated with a risk of recurrence of 2.28 ; 95\% CI: $1.29-4.03$ ( $p=$ $0.0046)$. Although DFS was significantly affected by clinical node involvement $(p=0.021)$. The tumour stage, initial BMI, menopausal status and treatment by hormonotherapy having a significant influence on DFS or on OS was not observed.

\section{Discussion}

In this study, we demonstrate a relationship between weight variation during polychemotherapy treatment and both poorer disease-free survival and overall survival after diagnosis of breast cancer.

The present study is in agreement with previous studies which have found that overweight at the time of diagnosis increased both breast cancer recurrence and mortality. This result has been largely demonstrated in U.S. populations [25-27]. The poorer prognosis of obesity at diagnosis could be explained by the fact that overweight women tend to be diagnosed with later stage cancer and therefore more adverse tumour characteristics than normal weight women [28]. For some authors, this association is restricted to women who detected their own cancer and not spread amongst cases detected by either screening mammography or clinical breast examination [29]. Additionally, lower screening rates may partly explain the higher breast cancer mortality in obese women [30]. In agreement with this, in our population who were diagnosed 20 years ago, when no screening mammography was systematically carried out, we observed a striking association between BMI and tumour size.

In our series however, with a median WV equal to zero during chemotherapy treatment of breast cancer 


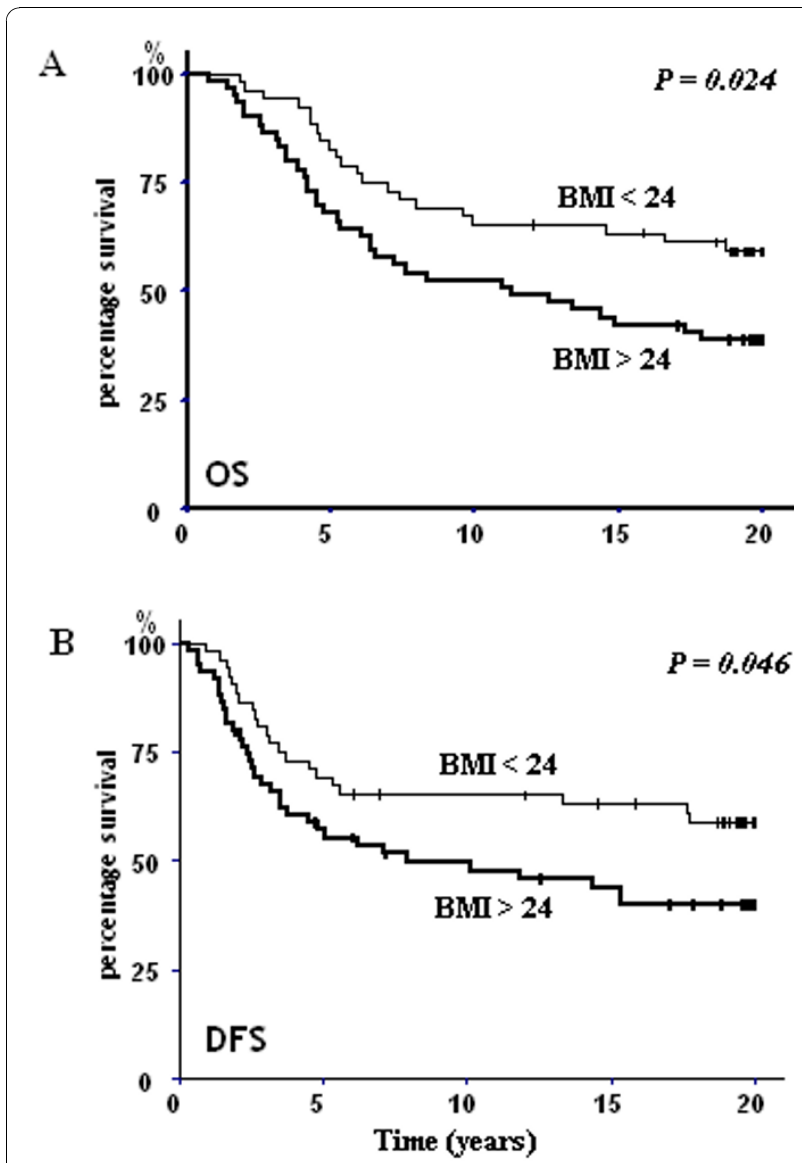

Figure 1 Kaplan-Meier overall survival (OS) (A) and deseasefree survival (DFS) (B) of patients whom initial BMI was $<24$ $\mathrm{kg} / \mathrm{m}^{2}(\mathrm{BMI}<24)$ and $>24 \mathrm{~kg} / \mathrm{m}^{2}(\mathrm{BMI}>24)$.

patients, $31 \%$ of our population presented a significant weight variation (> 5\%) whereas $68 \%$ had maintained their weight. Our findings of no significant median WV during chemotherapy treatment are in contrast with the vast majority of studies conducted in North America, which have generally reported an average weight gain ranging from 1.7 to $4.4 \mathrm{~kg}$ during the years that follow diagnosis in women treated by chemotherapy $[5,31,32]$. On the other hand, one study carried out in a Korean breast cancer population has already observed a lack of overall weight gain, with $10.4 \%$ of the population gaining more than $5 \%$ of baseline body weight at 1 year [31]. Regarding the baseline mean BMI, we can observe that populations who did not display a significant weight gain during chemotherapy treatment, including ours, are leaner (mean BMI of $24.4 \mathrm{~kg} / \mathrm{m} 2$ in our study, $23.5 \mathrm{~kg} /$ $\mathrm{m} 2$ in Korean study) than the ones used in the U.S. studies [5] in which the mean BMI varied from to 26.3 to $27.4 \mathrm{~kg} / \mathrm{m} 2$ [18,32]. Moreover, one possible explanation is that the chemotherapy regimen administered to our patients incorporated anthracycline-based therapy as
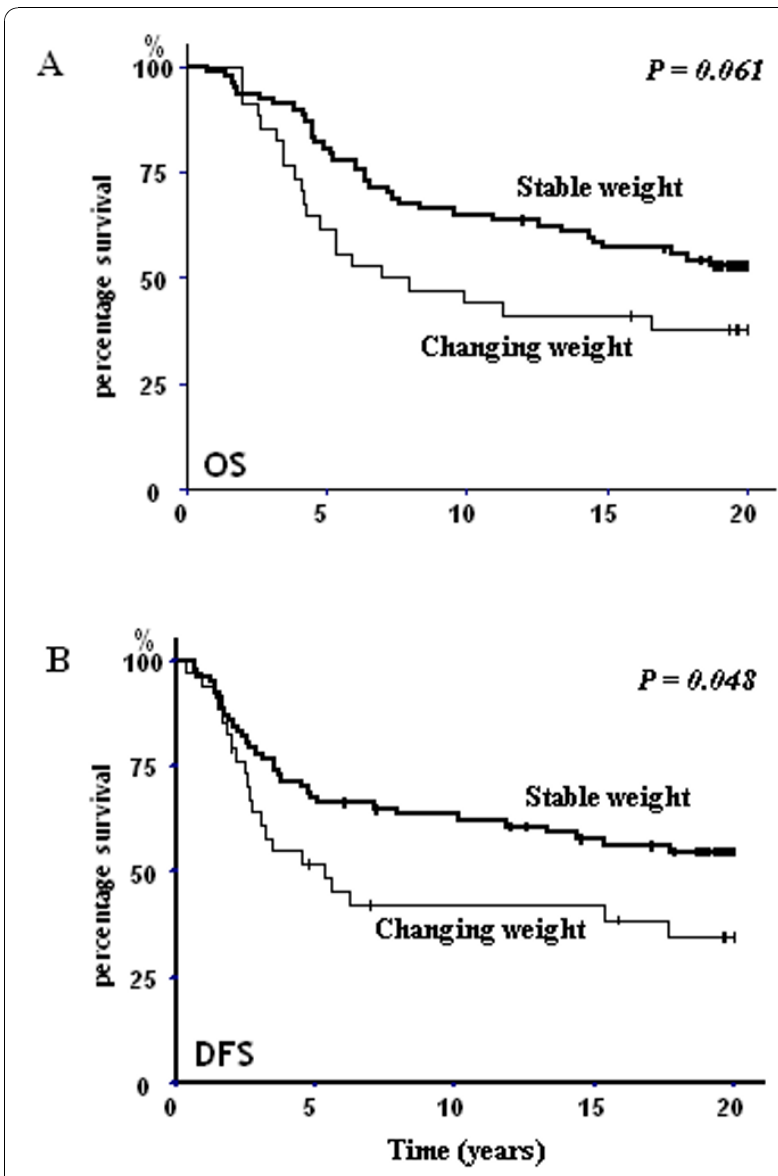

Figure 2 Kaplan-Meier overall survival (OS) (A) and deseasefree survival (DFS) (B) of patients whom weight variation was $<5 \%$ (stable) and $>5 \%$ (changing weight).

reported by Han and al. [33], whereas the majority of the earlier previous studies that observed a weight gain, involved non-anthracycline-based regimen. Other retrospective and prospective reports have not demonstrated increased weight gain with anthracycline-containing regimens compared with other regimens $[10,11]$. Fisher et al. [34] noted that $14.4 \%$ of patients receiving treatment with the $\mathrm{AC}$ regimen gained $\geq 5 \%$ over pretreatment weight compared with $42.2 \%$ of patient receiving CMF. This result was comparable to our result (14\% gained weight) indeed the fact that patient accrual took place prior to the widespread use of $5-\mathrm{HT}_{3}$ receptor antagonists in the two studies (cancer-related treatment currently used to reduce the impact of nausea and emesis associated with anthracycline use).

The long-term follow-up of patients who received an anthracycline-based chemotherapy in this study demonstrates that weight variation may not only influence recurrence, but also patient outcome. In multivariate analysis, clinical node involvement was still significant, thus, weight change was the strongest 
Table 2 Multivariate Cox model for overall survival (OS) and desease-free survival (DFS)

\begin{tabular}{|c|c|c|c|c|c|c|c|c|}
\hline \multirow[t]{2}{*}{ Category } & \multicolumn{4}{|l|}{ OS } & \multicolumn{4}{|l|}{ DFS } \\
\hline & $e / n$ & RR & $95 \%-\mathrm{Cl}$ & $\mathbf{P}$ & $e / n$ & RR & $95 \%-\mathrm{Cl}$ & $\mathbf{P}$ \\
\hline Weight variation & & & & $0.0082^{*}$ & & & & $0.0046^{*}$ \\
\hline$<5 \%$ (reference) & $36 / 77$ & 1.00 & & & $34 / 77$ & 1.00 & & \\
\hline$>5 \%$ & $21 / 34$ & 2.11 & $1.21-3.66$ & & $21 / 34$ & 2.28 & $1.29-4.03$ & \\
\hline Clinical Node Involement & & & & 0.054 & & & & $0.021^{*}$ \\
\hline NO (reference) & $22 / 55$ & 1.00 & & & $23 / 55$ & 1.00 & & \\
\hline N1 & $30 / 49$ & 1.61 & $0.99-2.61$ & & $27 / 49$ & 1.78 & $1.09-2.91$ & \\
\hline N2 & $4 / 6$ & 2.59 & $0.98-6.80$ & & $4 / 6$ & 3.18 & $1.19-8.49$ & \\
\hline N3 & $1 / 1$ & 4.16 & $0.99-16.40$ & & $1 / 1$ & 5.66 & $1.29-24.76$ & \\
\hline Tumor stage & & & & 0.084 & & & & 0.14 \\
\hline T1 (reference) & $6 / 21$ & 1.00 & & & $7 / 21$ & 1.00 & & \\
\hline $\mathrm{T} 2$ & $24 / 49$ & 1.32 & $0.96-1.81$ & & $25 / 49$ & 1.17 & $0.85-1.60$ & \\
\hline $\mathrm{T} 3$ & $10 / 17$ & 1.74 & $0.93-3.27$ & & $7 / 17$ & 1.37 & $0.73-2.57$ & \\
\hline T4 & $17 / 24$ & 2.30 & $0.90-5.90$ & & $16 / 24$ & 1.60 & $0.60-4.13$ & \\
\hline Initial BMI & & & & 0.20 & & & & 0.33 \\
\hline$<24 \mathrm{~kg} / \mathrm{m} 2$ & $21 / 52$ & 1.00 & & & $21 / 52$ & 1.00 & & \\
\hline$\geq 24 \mathrm{~kg} / \mathrm{m} 2$ & $36 / 59$ & 1.49 & $0.81-2.74$ & & $34 / 59$ & 1.59 & $0.86-2.93$ & \\
\hline Menopausal status & & & & 0.79 & & & & 0.46 \\
\hline Premenopausal (reference) & $21 / 50$ & 1.00 & & & $23 / 50$ & 1.00 & & \\
\hline Menopausal & $36 / 61$ & 1.09 & $0.59-1.99$ & & $32 / 61$ & 0.96 & $0.53-1.76$ & \\
\hline Hormonotherapy & & & & 0.81 & & & & 0.90 \\
\hline no (reference) & $34 / 67$ & 1.00 & & & $36 / 67$ & 1.00 & & \\
\hline yes & $23 / 44$ & 0.93 & $0.53-1.65$ & & $19 / 14$ & 0.80 & $0.44-1.14$ & \\
\hline
\end{tabular}

* $P$ value considered statistically significant $(p<0.05)$.

All the variable in the table were mutually adjusted for each other.

parameter associated with OS and DFS in our series. Literature on prognostic value of weight variation is mixed and not easily comparable. These studies that generally evaluated post-diagnosis weight variation on different periods which varied from a few months to a few years after diagnosis, including different treatments (chemotherapy and or hormonotherapy, radiation only...), did not use the same prognostic outcomes, and sometimes with a short median of follow-up. Among the few studies which evaluated the prognostic value of weight change after breast cancer diagnosis, four studies have shown a poor prognosis $[8,14-16]$ whereas five reported no relationship [9,17-19].

The majority of studies observed an impact of weight gain on patient outcome. The largest study to date included 5,204 Nurses' Health Study participants diagnosed with non-metastatic breast cancer between 1976 and 2000 treated with chemotherapy and/or hormonal therapy [14]. This study reported an increased risk of recurrence, breast cancer death and total mortality in patients who gained more than $2 \mathrm{~kg} / \mathrm{m}^{2}$ by comparison to patients who maintained their weight. However this relationship was found only among women who never smoked and the definition of recurrence included reported lung, bone or brain cancer, but excluded any local recurrences in the ipsilateral breast or new primaries in the contralateral breast. Camoriano et al. reported weight gain having a significant effect on overall survival during treatment with cyclophosphamide, fluorouracile and prednisolone (CFD) or CFD plus tamoxifen, but not on recurrence and this only for premenopausal women [8]. Two other studies conducted prior the common use of anthracycline-based chemotherapy reported a correlation between weight gain and overall survival and/or disease-free survival (without defining which events were included) $[15,16]$.

Only one recent study reported some evidence that women with early stage breast cancer treated with chemotherapy and/or radiation and tamoxifen who had large weight loss (>10\%) were at higher risk of 


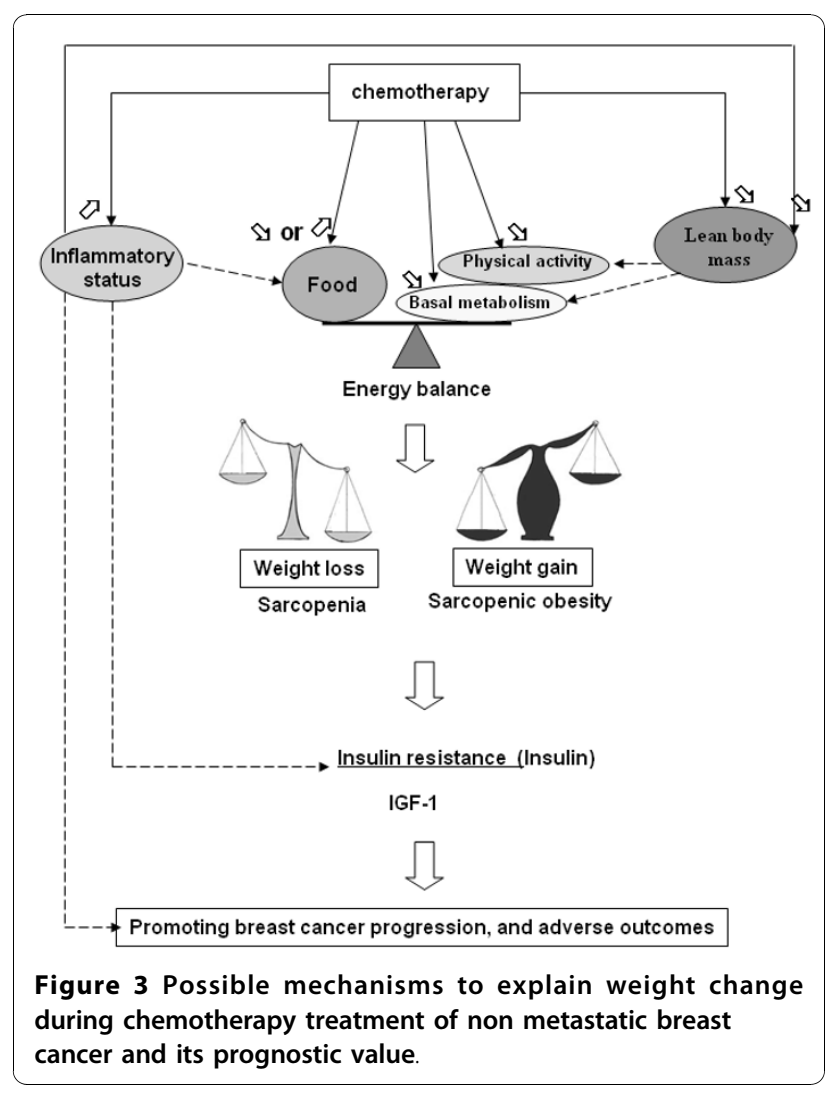

recurrence and death compared to women with no weight variation. This elevated risk was more pronounced among women who were obese before diagnosis or who had ER- or PR- tumours [19]. One obvious explanation for significant weight loss being related to an increased risk of death could be that the breast cancer disease process itself caused weight loss.

Literature on the prognostic value of weight variation reported some evidence that women who had gained or lost weight have a higher risk of recurrence and death compared to women with no weight variation. So, we chose to group women who gained weight with those who lost weight as a weight changing group. We hypothesized that weight change reflected a metabolic disorder by comparison to women who maintained their weight with an energy balance in equilibrium (Figure 3). Chemotherapy induced a decrease in energy expenditure (lowered basal metabolic rate, thermogenesis, and physical activity [4]) and different modifications in dietary intake (increase in appetite [14] or decreased ingestion of food due to chemotherapy related nausea and emesis) that can lead to weight gain or loss according to dietary behaviour of patient. Moreover, women with breast cancer receiving adjuvant chemotherapy underwent unfavourable changes in body composition with lean body loss due to a negative nitrogen balance [35] even in the absence of an overall weight change [4]. A lot of data has demonstrated that weight gain during chemotherapy was indicative of sarcopenic obesity [33]. Indeed, chemotherapy for breast cancer like taxane and anthracycline can increase inflammation [36,37] which played a central role on different modifications induced by chemotherapy. Inflammatory cytokines interfered with the satiety centre [38] and catabolism of skeletal muscle protein responsive of sarcopenia but not independently of any of the considered obesity indexes [39].

Several mechanisms have been proposed to explain the adverse effect of weight gain on risk of recurrence and mortality. First, weight gain and all associated metabolic disorders may predispose women to diabetes or heart disease, thereby predisposing them to morbidity and mortality [6]. However, in our study, only a few patients died from causes other than breast cancer (14\%). One possible mechanism was a greater aromatase activity in the excess adipose tissue [40] and an inhibition of synthesis of sex hormone-binding globuline associated with an increased in free estradiol level which stimulates neoplasic cells [41].

Insulin resistance may be a common mechanism to explain the poor prognosis of patients who experienced a weight loss or a weight gain (Figure 3). Indeed, insulin resistance has been shown in variety of cancer patients with body-weight loss [42], but was also seen in overweight women [43]. Fasting serum insulin concentration has been directly associated with an increase in both distant recurrence and death in women previously treated for breast cancer $[42,43]$. There is a strong biological rational for an adverse prognostic effect of insulin. Insulin, a member of a family of growth factors that includes IGF-I and IGF-II, exerts a mitogenic effect on malignant breast cancer cells though IGF-I receptor. It is also hypothesized that visceral obesity increases both insulinlike growth factors (IGF-I, IGF-II) which stimulates the synthesis of sex steroid hormones [31] that are involved in the regulation of normal and malignant growth of epithelial breast cells. Several studies have reported a reduction in circulating concentration of IGF-I in malignant disease, which may also have been associated with nutritional decline and systemic inflammation [44]. Yoshikawa et al. hypothesized that inflammatory reactions might be involved in the development of insulin resistance [42]. Moreover, few studies reported an association between elevated inflammatory cytokines and a worse prognosis in breast cancer patients $[45,46]$.

Further research is needed to understand the biological mechanisms underlying the relationship between weight variation and breast cancer growth with exploration of insulin resistance in association with body composition, measurement of energy expenditures, calorie intake and inflammatory reaction. 
The current study had several limitations including its study design (retrospective chart review) and a relatively small sample size to draw a conclusion on the independent effect of weight variation. Some interesting covariates like "normal " weight prior diagnosis, smoking status, physical activity or sociodemographic aspects (education) have not been explored because of the lack of this data in patients' medical records. Additionally, more detailed measurement of body shape and fat content are lacking. Currently a long-term measurement of weight during patient follow-up is ongoing and could offer the possibility to explore weight variation after treatment which could also affect prognostic outcomes.

\section{Conclusions}

Our results suggest that weight change during anthracycline-based treatment of early stage breast cancer is associated with increased risk of recurrence and poorer survival, though they may require additional confirmation. Furthermore, while we have speculated on potential biological targets, more research is needed to understand the biological mechanisms underlying the relationship between weight variation and breast cancer growth.

\section{Abbreviations}

W: weight variation; BMI: Body Mass Index; TNM: tumor-node-metastasis; DFS: disease free survival; OS: overall survival; $\mathrm{Cl}$ : confidence Interval.

\section{Acknowledgements and funding}

The Authors thank Delphine Roux and Delphine Crouzet for acquisition of data, and David Belin for copyedit the paper.

\section{Author details \\ 'Division of Clinical Research, Centre Jean Perrin, Clermont-Ferrand, F-63011 France; University Clermont 1, UFR Médecine, Clermont-Ferrand, F-63001 France; Centre d'Investigation Clinique, Clermont-Ferrand, F-63001 France. ${ }^{2}$ UMR 990 INSERM/UdA, Clermont-Ferrand, F-63000 France. ${ }^{3}$ Oncology department, Centre Jean Perrin, Clermont-Ferrand, F-63011 France; University Clermont 1, UFR Médecine, Clermont-Ferrand, F-63001 France; Centre d'Investigation Clinique, Clermont-Ferrand, F-63001 France. ${ }^{4}$ Surgery department, Centre Jean Perrin, Clermont-Ferrand, F-63011 France; University Clermont 1, UFR Médecine, Clermont-Ferrand, F-63001 France; Centre d'Investigation Clinique, Clermont-Ferrand, F-63001 France.}

\section{Authors' contributions}

ET contributed to the data collection, analysis and wrote the paper. ST and $\mathrm{OL}$ contributed to the data collection and helped in in writing the final draft. FK contributed to the data analysis. EG, CA, EP helped in writing the final draft. $P G, M A M R, P C$ and $X D$ contributed to patient recruitment. $P C$ and $X D$ contributed to the study design and analysis and have been involved in drafting the manuscript. All authors read and approved the final manuscript.

\section{Competing interests}

The authors declare that they have no competing interests.

Received: 10 December 2009 Accepted: 25 November 2010 Published: 25 November 2010

\section{References}

1. NIH Consens Statement: Adjuvant therapy for Breast Cancer 2000, 17:1-35.
2. Carmichael AR: Obesity and prognosis of breast cancer. Obesity reviews: an official journal of the International Association for the Study of Obesity 2006, 7:333-340.

3. Goodwin PJ, Esplen MJ, Wincour J, Butler K, Pritchard KI: Development of a weight management program in women with newly diagnosed locoregional breast cancer. In Pschosomatic Obstetrics and Gynecology. Edited by: Bitzer J, Stauber M. Bologna: Monduzzi Editore, International Proceedings Division; 1995:491-496.

4. Demark-Wahnefried W, Peterson BL, Winer EP, Marks L, Aziz N, Marcom PK, Blackwell K, Rimer BK: Changes in weight, body composition, and factors influencing energy balance among premenopausal breast cancer patients receiving adjuvant chemotherapy. J Clin Oncol 2001, 19:2381-2389.

5. Saquib N, Flatt SW, Natarajan L, Thomson CA, Bardwell WA, Caan B, Rock $C L$, Pierce JP: Weight gain and recovery of pre-cancer weight after breast cancer treatments: evidence from the women's healthy eating and living (WHEL) study. Breast Cancer Res Treat 2007, 105:177-186.

6. Demark-Wahnefried W, Winer EP, Rimer BK: Why women gain weight with adjuvant chemotherapy for breast cancer. J Clin Oncol 1993, 11:1418-1429.

7. Demark-Wahnefried W, Rimer BK, Winer EP: Weight gain in women diagnosed with breast cancer. J Am Diet Assoc 1997, 97:519-526, 529; quiz 527-528.

8. Camoriano JK, Loprinzi CL, Ingle JN, Therneau TM, Krook JE, Veeder MH: Weight change in women treated with adjuvant therapy or observed following mastectomy for node-positive breast cancer. J Clin Oncol 1990, 8:1327-1334.

9. Goodwin PJ, Panzarella T, Boyd NF: Weight gain in women with localized breast cancer-a descriptive study. Breast Cancer Res Treat 1988, 11:59-66.

10. Levine EG, Raczynski JM, Carpenter JT: Weight gain with breast cancer adjuvant treatment. Cancer 1991, 67:1954-1959.

11. Makari-Judson G, Judson CH, Mertens WC: Longitudinal patterns of weight gain after breast cancer diagnosis: observations beyond the first year. Breast J 2007, 13:258-265.

12. Rock $\mathrm{CL}$, Demark-Wahnefried W: Nutrition and survival after the diagnosis of breast cancer: a review of the evidence. J Clin Oncol 2002, 20:3302-3316.

13. Hess LM, Barakat R, Tian C, Ozols RF, Alberts DS: Weight change during chemotherapy as a potential prognostic factor for stage III epithelial ovarian carcinoma: a Gynecologic Oncology Group study. Gynecol Oncol 2007, 2:260-265

14. Kroenke $\mathrm{CH}$, Chen WY, Rosner B, Holmes MD: Weight, weight gain, and survival after breast cancer diagnosis. J Clin Oncol 2005, 23:1370-1378.

15. Bonomi PBN, Fishman D: Weight gain during breast cancer evaluated in relation to disease-free survival (DFS). Breast Cancer Research And Treatment 1984, 4:339.

16. Chlebowski RT, Weiner JM, Reynolds R, Luce J, Bulcavage L, Bateman JR: Long-term survival following relapse after 5-FU but not CMF adjuvant breast cancer therapy. Breast Cancer Res Treat 1986, 7:23-30.

17. Heasman KZ, Sutherland HJ, Campbell JA, Elhakim T, Boyd NF: Weight gain during adjuvant chemotherapy for breast cancer. Breast Cancer Res Treat 1985, 5:195-200

18. Caan BJ, Kwan ML, Hartzell G, Castillo A, Slattery ML, Sternfeld B, Weltzien E: Pre-diagnosis body mass index, post-diagnosis weight change, and prognosis among women with early stage breast cancer. Cancer Causes Control 2008, 19:1319-1328.

19. Caan BJ, Emond JA, Natarajan L, Castillo A, Gunderson EP, Habel L, Jones L, Newman VA, Rock CL, Slattery ML, Stefanick ML, Sternfeld B, Thomson CA, Pierce JP: Post-diagnosis weight gain and breast cancer recurrence in women with early stage breast cancer. Breast Cancer Res Treat 2006, 99:47-57.

20. Marret $H$, Perrotin $F$, Bougnoux $P$, Descamps $P$, Hubert $B$, Lefranc $T$, Le Floch O, Lansac J, Body G: Low body mass index is an independent predictive factor of local recurrence after conservative treatment for breast cancer. Breast Cancer Res Treat 2001, 66:17-23.

21. Sobin LHWC: TNM Classification of Malignant Tumours. New York, NY: UICC, Wiley-Liss; 2002.

22. Kaplan ELMP: Non Parametric estimation for incomplete observations. J Am Stat Assoc 1958, 53:457-481

23. Cox DR: Regression Models and Life-Tables. Journal of the Royal Statistical Society. Series B (Methodological) 1972, 34:187-220. 
24. Kwiatkowski F, Girard M, Hacene K, Berlie J: Sem: a suitable statistical software adaptated for research in oncology. Bull Cancer 2000, 87:715-721.

25. Pierce JP, Stefanick ML, Flatt SW, Natarajan L, Sternfeld B, Madlensky L, AlDelaimy WK, Thomson CA, Kealey S, Hajek R, Parker BA, Newman VA, Caan $B$, Rock $C L$ : Greater survival after breast cancer in physically active women with high vegetable-fruit intake regardless of obesity. J Clin Oncol 2007, 25:2345-2351.

26. Daling JR, Malone KE, Doody DR, Johnson LG, Gralow JR, Porter PL: Relation of body mass index to tumor markers and survival among young women with invasive ductal breast carcinoma. Cancer 2001, 92:720-729.

27. Chlebowski RT, Aiello E, McTiernan A: Weight loss in breast cancer patient management. J Clin Oncol 2002, 20:1128-1143.

28. Cui Y, Whiteman MK, Flaws JA, Langenberg P, Tkaczuk KH, Bush TL: Body mass and stage of breast cancer at diagnosis. Int J Cancer 2002, 98:279-283.

29. Reeves MJ, Newcomb PA, Remington PL, Marcus PM, Mackenzie WR: Body mass and breast cancer. Relationship between method of detection and stage of disease. Cancer 1996, 77:301-307.

30. Maruthur NM, Bolen S, Brancati FL, Clark JM: Obesity and mammography: a systematic review and meta-analysis. J Gen Intern Med 2009, 24:665-677.

31. Demark-Wahnefried W, Rock CL: Nutrition-related issues for the breast cancer survivor. Semin Oncol 2003, 30:789-798.

32. Irwin ML, McTiernan A, Baumgartner RN, Baumgartner KB, Bernstein L, Gilliland FD, Ballard-Barbash R: Changes in body fat and weight after a breast cancer diagnosis: influence of demographic, prognostic, and lifestyle factors. J Clin Oncol 2005, 23:774-782.

33. Han HS, Lee KW, Kim JH, Kim SW, Kim IA, Oh DY, Im SA, Bang SM, Lee JS: Weight changes after adjuvant treatment in Korean women with early breast cancer. Breast Cancer Res Treat 2009, 114:147-153.

34. Fisher B, Brown AM, Dimitrov NV, Poisson R, Redmond C, Margolese RG, Bowman D, Wolmark N, Wickerham DL, Kardinal CG, et al: Two months of doxorubicin-cyclophosphamide with and without interval reinduction therapy compared with 6 months of cyclophosphamide, methotrexate, and fluorouracil in positive-node breast cancer patients with tamoxifennonresponsive tumors: results from the National Surgical Adjuvant Breast and Bowel Project B-15. J Clin Oncol 1990, 8:1483-1496.

35. Gudny Geirsdottir O, Thorsdottir I: Nutritional status of cancer patients in chemotherapy; dietary intake, nitrogen balance and screening. Food Nutr Res 2008, 52:10, 3402/fnr.v52i0.1856.

36. Mills PJ, Ancoli-Israel S, Parker B, Natarajan L, Hong S, Jain S, Sadler GR, von Känel R: Predictors of inflammation in response to anthracycline-based chemotherapy for breast cancer. Brain Behav Immun 2008, 22:98-104.

37. Tsavaris N, Kosmas C, Vadiaka M, Kanelopoulos P, Boulamatsis D: Immune changes in patients with advanced breast cancer undergoing chemotherapy with taxanes. $\mathrm{Br} J$ Cancer 2002, 87:21-27.

38. Durham WJ, Dillon EL, Sheffield-Moore M: Inflammatory burden and amino acid metabolism in cancer cachexia. Curr Opin Clin Nutr Metab Care 2009, 12:72-77.

39. Cesari M, Kritchevsky SB, Baumgartner RN, Atkinson HH, Penninx BW, Lenchik L, Palla SL, Ambrosius WT, Tracy RP, Pahor M: Sarcopenia, obesity, and inflammation - results from the Trial of Angiotensin Converting Enzyme Inhibition and Novel Cardiovascular Risk Factors study. Am J Clin Nutr 2005, 82:428-434.

40. Loi S, Milne RL, Friedlander ML, McCredie MR, Giles GG, Hopper JL, Phillips KA: Obesity and outcomes in premenopausal and postmenopausal breast cancer. Cancer Epidemiol Biomarkers Prev 2005, 14:1686-1691.

41. Kaye SA, Folsom AR, Soler JT, Prineas RJ, Potter JD: Associations of body mass and fat distribution with sex hormone concentrations in postmenopausal women. Int J Epidemiol 1991, 20:151-156.

42. Yoshikawa T, Noguchi Y, Doi C, Makino T, Nomura K: Insulin resistance in patients with cancer: relationships with tumor site, tumor stage, bodyweight loss, acute-phase response, and energy expenditure. Nutrition 2001, 17:590-593.

43. Goodwin PJ, Ennis M, Pritchard KI, Trudeau ME, Koo J, Madarnas Y, Hartwick W, Hoffman B, Hood N: Fasting insulin and outcome in earlystage breast cancer: results of a prospective cohort study. $J$ Clin Oncol 2002, 20:42-51.
44. Simons JP, Schols AM, Buurman WA, Wouters EF: Weight loss and low body cell mass in males with lung cancer: relationship with systemic inflammation, acute-phase response, resting energy expenditure, and catabolic and anabolic hormones. Clin Sci (Lond) 1999, 97:215-223.

45. Pierce BL, Ballard-Barbash R, Bernstein L, Baumgartner RN, Neuhouser ML, Wener MH, Baumgartner KB, Gilliland FD, Sorensen BE, McTiernan A, Ulrich CM: Elevated biomarkers of inflammation are associated with reduced survival among breast cancer patients. J Clin Oncol 2009, 27:3437-3444.

46. Coussens LM, Werb Z: Inflammation and cancer. Nature 2002, 420:860-867.

\section{Pre-publication history}

The pre-publication history for this paper can be accessed here: http://www.biomedcentral.com/1471-2407/10/648/prepub

\section{doi:10.1186/1471-2407-10-648}

Cite this article as: Thivat et al:. Weight change during chemotherapy changes the prognosis in non metastatic breast cancer for the worse. BMC Cancer 2010 10:648.

\section{Submit your next manuscript to BioMed Central and take full advantage of:}

- Convenient online submission

- Thorough peer review

- No space constraints or color figure charges

- Immediate publication on acceptance

- Inclusion in PubMed, CAS, Scopus and Google Scholar

- Research which is freely available for redistribution

Submit your manuscript at www.biomedcentral.com/submit
C Biomed Central 